\title{
INTENCIONES, PROPOSICIONES Y DOS TIPOS DE BONDAD *
}

\author{
HÉctor-Neri Castañeda
}

UNIVERSIDAD DE INDIANA

Convenciones. Las comillas sencillas, aplicadas a palabras, frases u oraciones forman, como de costumbre, los nombres de las palabras, frases $\mathrm{u}$ oraciones a que se aplican. Las comillas dobles, aplicadas a una oración o frase forman el nombre de una proposición, o función proposicional, o entidad no especificada aquí y ocasionalmente formulable por medio de la oración o frase en cuestión. Asumimos simplemente que hay métodos para determinar en cada ocasión qué propiedad o función proposicional expresa una oración dada.

Se asumirá que los términos 'estado de hechos', 'proposición' y 'enunciado' se refieren al mismo tipo de entidad. El primero es el más neutral y objetivo; el segundo pone el acento en las proposiciones como contextos de actos lingüísticos. Naturalmente, al adoptar esta convención adopto el uso de las frases 'estado de hechos verdadero' y 'estado de hechos falso'. Concedo que estos usos son raros. ${ }^{1}$

* Una versión anterior de este artículo, dedicada a Charles Baylis, apareció en la antología de homenaje a Charles Baylis, preparada por Paul Welsh, Fact. Value and Perception (Durham, N. C.: Duke University Press, 1975). Esta traducción fue hecha por Alejandro Herrera Ibáñez, en mayo 1980.

1 Fact. Value and Perception fue reseñada por Bernard Mayo en Philosophical Books, vol. 18, n? 2, May 1976. Mayo ofrece una crítica global de mi estudio, a saber:

El ensayo de Héctor-Neri Castañeda... es seriamente defectuoso desde un principio porque identifica la bondad de los estados de cosas [states of affairs] con la bondad de las proposiciones (94).

Desafortunadamente Mayo jamás explica qué consecuencias falsas se derivan de ese error serio. Esa parsimonia de Mayo es de gran importancia, pues su ataque se basa en una estipulación terminológica que adopté en ese estudio, y continúo adoptando en éste. No es evidente que existan dos tipos de entidades, uno ilustrado por entes a los que se llama exclusivamente estados de cosas, y otro por entes a los que se llama exclusivamente proposiciones. Pero supongamos que los haya. En carta del 4 de agosto de 1976 le pedí a Mayo una aclaración. Dicha carta todavía no ha tenido respuesta. Le rogué que me explicara a cuál de los tipos siguientes corresponde ese "defecto serio" de mi estipulación terminológica: 


\section{Introducción}

La idea central de este ensayo es que los conceptos (o, si se quiere, las propiedades) axiológicos deben distinguirse claramente de los conceptos (o propiedades) deónticos. Ésta es una tesis clásica que ha sido defendida, en este siglo, por H. A. Prichard ${ }^{2}$ y por William David Ross. ${ }^{3}$ Pero el argumento aquí desarrollado es completamente distinto de los argumentos de otros filósofos que han atacado el problema. Es un argumento novedoso que durante veinticinco años ha estimulado el interés de sucesivas promociones de alumnos que han tomado mi curso de Teorías Éticas del Siglo $\mathbf{x x}$.

Puede ser útil formular nuestro problema dentro de un marco de problemas más generales acerca de la bondad ( $\mathrm{y}$ de la maldad). Para comenzar, se dice, y a menudo correctamente, de entidades de todas categorías y tipos, que son buenas o malas. Atribuímos bondad a cosas materiales como, por ejemplo, cuando juzgamos:

(1) Un autor escribe una monografía zoológica y dice en la introducción que usará las expresiones 'vaca' y 'elefante' para referirse a la misma clase de animales. Usa las palabras, como lo promete, de manera intercambiable, pero las fotos y dibujos son todos de elefantes, y las descripciones que da son todas verdaderas de elefantes. ¿En dónde está el error serio del contenido zoológico de la monografia?

(2) Colón creía que Cuba era China. ¿Perjudicó ese error sus descripciones de la fauna o de la flora que encontró en esa isla?

(3) Una dama habla del presidente Kennedy. Un oyente reclama que ella está confundiendo al presidente Kennedy con Robert Kennedy. En este caso la confusión consta de tres partes: el conjunto de verdades ( $y$ tiene que haber tales) sobre el presidente Kennedy que la dama sabe; el conjunto de verdades (y tiene que haberlas) sobre Robert Kennedy que la dama sabe; y el conjunto de proposiciones de identidad de la forma "El tal y tal es el cual y cual", en que el tal y tal es Robert Kennedy y el cual y cual es el presidente Kennedy.

En resumen, si el lector cree, como Mayo, que las proposiciones y los estados de cosas son entes distintos, o bien hay en mi ensayo un uso anormal de la palabra 'proposición' o de la frase 'estado de cosas' - cuál uso anormal es un precioso problema para el lector-, o bien hay en mi ensayo un error posible acerca de la bondad de las proposiciones o de la verdad de los estados de cosas - de nuevo, esclarecer cuál es mi error, si en efecto hay tal error, es ejercicio valioso para el lector-, o bien cometo un error al creer que las proposiciones son estados de cosas, y viceversa, pero lo que digo sobre la bondad de las proposiciones y de los estados de cosas es correcto - pues sólo he tratado de lo que hay de común entre la bondad de las proposiciones y la bondad de los estados de cosas.

El caso (3) contiene una sugerencia acerca del análisis del concepto confundir a algo (individuo, clase, etc.) con otra cosa.

2 H. A. Prichard, "Does Moral Philosophy Rest on a Mistake?" Mind n 21 (1912), reimpreso en H. A. Prichard, Moral Obligation. Oxford, England: Clarendon Press, 1949; y en muchas antologías.

3 D. Ross, The Right and the Good. Oxford, England: Clarendon Press, 1930, cap. 1 . 
(A.I) Éste es un buen filete.

Predicamos bondad de acciones, como en:

(B.1) Es bueno que esperemos a Enriqueta.

(B.2) Es una buena cosa esperar a Enriqueta.

Atribuimos bondad a personas, como cuando decimos:

(C.I) Ulises es un buen estudiante.

(C.2) Ulises es un buen hombre.

Al menos aparentemente, atribuimos bondad a proposiciones o estados de hechos, como en:

(E.1) Fue bueno que Ulises viniera.

Predicamos bondad de intenciones, por ejemplo:

(F.1) La intención de Ulises al venir fue buena.

Y para hacer las cosas más desconcertantes, parece que también predicamos relaciones de valor entre agentes y acciones o estados de hechos. Así, en tanto que en los ejemplos precedentes la bondad parece ser una cualidad, o una propiedad monádica o no relacional, en los siguientes ejemplos la bondad parece ser una relación entre una persona y un estado de hechos (o proposición) o una acción:

(G.l) Fue bueno de parte de Ulises venir;

(G.1') Fue bueno de parte de Ulises haber venido;

(L.1) Fue bueno de parte de Ulises que viniera;

(J.I) Fue bueno para Enriqueta que Ulises viniera.

Los variados usos de la palabra 'bueno' suscitan una serie de problemas interesantes tanto respecto a su naturaleza como a la naturaleza de los conceptos de bondad, maldad y valor en general. El hecho fundamental es éste: se usen, o no, las palabras 'bueno' y 'malo' para predicar propiedades - como algunos filósofos quisieran-, estas palabras aparecen, como queda ilustrado arriba, en una diversidad desconcertante de construcciones sintáctico-semánticas. Se requiere una explicación comprensiva y unitaria de estas construcciones. Cualquiera que sea la posición que uno sostenga acerca de los valores, la bondad y la maldad se presentan a la conciencia en pensamientos acerca de valores, como propiedades o modificaciones de algún tipo. Una descripción detallada de la fenomenología de dichas propiedades es al mismo tiempo una tarea ineludible de elucidación filosófica y una prueba necesaria de la adecuación de toda teoría reduccionista que quiera eliminar o negar el carácter de propiedad de la bondad y la maldad. Así pues, con una descripción fenomenológica como propósito, nos sentimos metodológicamente justificados al adoptar una formulación o postura ostensiblemente objetiva.

En la medida en que la bondad aparece como propiedad de los ejemplos $(A .1)-(J .1)$, nos enfrentamos a preguntas como: 
(I) ¿El adjetivo 'bueno' predica de varias maneras una y la misma propiedad transcategorial, que pasa a través de los rangos lógicos u ontológicos, o hay varias propiedades diferentes, una para cada rango?

(II) Si con el adjetivo 'bueno' se predican varias propiedades, țes una de ellas primaria, siendo las otras analizables en términos de ella?

(III) ¿Es la bondad primaria una propiedad de estados de hechos o proposiciones, o es una propiedad de propiedades?

(IV) ¿Hay más de una bondad primaria? ¿Cuántas más?

En otro artículo ${ }^{4}$ he sostenido que:

$A$. La bondad de las propiedades es derivada: las propiedades son buenas en el sentido de que hacen buenos los estados de hechos o proposiciones (véase la nota 1 para el posible contraste entre proposiciones y estados de cosas);

$B$. La bondad de los particulares es también derivada: es analizable en términos de la bondad y maldad de estados de hechos;

C. Los estados de hechos o proposiciones son los sujetos últimos de la predicación de valor.

En ese ensayo previo, sin embargo, no consideré juicios de valor aparentemente relacionales o relativos, como $(F .1)$ "La intención de Ulises al venir fue buena", (G.I) "Fue bueno de parte de Ulises venir", y $(J .1)$ "Fue bueno para Enriqueta que Ulises viniera". Aunque defendí la tesis $C$, o sea, que los estados de hechos son los sujetos de valor últimos o primarios, no llegué a proporcionar una respuesta a la pregunta (IV) respecto a si hay más de una bondad primaria. Aquí me propongo acercarme más a una respuesta a la pregunta (IV). Quiero continuar esta investigación inquiriendo sobre la diferencia entre $(E . I)$ "Fue bueno que Ulises viniera", y (G.I) "Fue bueno de parte de Ulises venir".

En este ensayo intentaré establecer dos tesis fenomenológicas:

$D$. Hay al menos dos bondades primarias e irreducibles;

$E$. Una bondad se aplica a estados de hechos (o proposiciones); la otra a intenciones y, más en general, a practiciones. Este término se explicará en seguida.

4 "On the Ultimate Subjects of Value Predication", en John W. Davis (ed.), Value and Valuation. Axiological Studies in honor of Robert S. Hartman. Knoxville: University of Tennessee Press, 1971. 
Parte de este artículo desarrollará el contraste entre proposiciones e intenciones. Este es el contraste entre proposiciones y practiciones, que he discutido con cierta extensión en otros estudios. ${ }^{5}$

Estrictamente hablando, ninguna de las bondades es realmente una propiedad; una es un operador o modalidad de proposiciones, y la otra es un operador o modalidad de intenciones y prescripciones. Es decir, en "Es bueno que Ulises viniera" tenemos una proposición que resulta de la proposición "Ulises vino" por medio de la "acción" del operador o conector expresada con el prefijo sintáctico 'es bueno que'. En 'es bueno que Ulises viniera' la palabra 'bueno' no funciona como un adjetivo aplicado a un nombre que nombra la proposición de que Ulises vino. La palabra 'bueno' si funciona de esa manera en la oración “ "Ulises vino" es bueno'. Y, ciertamente, debemos distinguir con mucha claridad entre las proposiciones de segundo orden (si las hay) expresables con la oración "Ulises vino" es bueno' y las proposiciones modales correspondientes de primer orden que expresa la oración "Es bueno que Ulises viniera". Consideraciones parecidas valen, mutatis mutandis, para 'Fue bueno de parte de Ulises venir'. Pero no entraremos en esta cuestión aquí. A veces, por conveniencia, para conformarnos a la tradición, hablaremos de propiedades de valor o de la bondad como una propiedad, usando el término 'propiedad' en un sentido amplio, sin implicar en lo más mínimo que, en un sentido preferible y estrecho de 'propiedad', los operadores se conciben mejor como no-propiedades.

\section{Las intenciones}

Como los vocabularios psicológicos y axiológicos ordinarios son tan complejos y confusos, no sería completamente inesperado que una persona usara ocasionalmente las siguientes dos oraciones para formular exactamente el mismo enunciado (o proposición, o estado de cosas):

(E.1) Fue bueno que Ulises viniera,

(G.1) Fue bueno por parte de Ulises venir.

Sin embargo, una sencilla reflexión sobre las convenciones del español revela que es más apropiado y natural usar dichas oraciones para formular dos enunciados completamente diferentes en cuanto al papel que

5 Especialmente en "Actions, Imperatives and Obligations", Aristotelian Society Proceedings, 68 (1967-68), 25-48. Ver también H. N. Castañeda, The Structure of Morality. Springfield, Ill.: Charles Thomas Publisher, 1974, caps. 2-5; y Thinking and Doing. Dordrecht-Holland/Boston: Reidel, 1975, caps. 4-7. 
cada uno asigna al agente, Ulises. Mientras que (E.1) coloca el valor en el estado de hechos "Ulises vino" como un todo, (G.1) coloca un valor especial (al menos eso parece) en Ulises. Dejemos, por tanto, que estas oraciones sean usadas en su forma más natural, y supongamos que en (E.l) y $(G .1)$ tenemos dos enunciados.

Claramenté, el enunciado (G.I) no es equivalente al enunciado (E.I). Ninguno de ellos, en efecto, implica al otro. Puede muy bien ser una buena cosa el que suceda que Ulises esté en el lugar en cuestión, y, sin embargo, puede no llegar a ser bueno por parte de él; en efecto, puede ser palpablemente malo, por parte de él, venir, debido a lo que tenia intención de hacer, haya o no haya llevado a cabo sus malas intenciones. $O$ sea, $(E .1)$ puede ser verdadero en tanto que $(G .1)$ es falso, de manera que (E.1) no implica (G.1). De manera similar, puede ser una mala cosa que Ulises viniera, aunque fue bueno por parte de él haber venido, debido a lo que tenía intención de hacer. O sea, $(G .1)$ no implica a su vez $(E .1)$.

La no equivalencia de arriba sugiere que (G.1) podría analizarse como

(G.1.b) Ulises vino y fue bueno que tuviera la intención de venir.

Puede pensarse que (G.1.b) no es suficientemente fuerte, en cuanto que la razón de afirmar (G.I) puede ser alabar a un hombre, no simplemente por encontrarse en el estado de tener la intención de venir, sino por haber alcanzado el estado de tener intención después de deliberar. Así pues, de acuerdo con esta sugerencia, (G.1) ha de analizarse como

(G.1.c) Ulises vino y fue (es) bueno que decidiera venir. ${ }^{6}$

Quizás no sea poco común, como se indicó arriba, que una persona use la oración (G.1) para formular un enunciado que podría expresarse apropiadamente con la oración (G.l.c). Sin embargo, las convenciones semánticas de nuestra lengua parecen hacer más adecuadamente expresable otro enunciado por medio de la oración (G.1). Me parece que ni (G.1.b) ni (G.1.c) pueden funcionar como formulaciones de ese enunciado más adecuado. Puede suceder que sea bueno que Ulises tenga la intención de hacer una cosa u otra, simplemente porque es bueno que él tenga la habilidad de adoptar intenciones (o de tomar decisiones), o porque, en general, es bueno que haya seres capaces de tener intenciones

6 Le debo esta sugerencia a Romane Clark. 
(o de tomar decisiones). Sin embargo, puede al mismo tiempo ser malo por parte de Ulises venir, porque su intención (o decisión) de venir es en sí misma mala. Esto es, para que el enunciado (G.l) sea verdadero, se requiere que los contenidos de tener intenciones (o de tomar decisiones) por parte de Ulises sean buenos, pero no se requiere que Ulises realice la buena acción de tener intenciones (o de tomar decisiones), o que él se encuentre en un buen estado de tener alguna intención (o de haber tomado alguna decisión). Así pues, el análisis de (G.1) es con mayor probabilidad el siguiente:

(G.1.d) Ulises vino y su intención de venir fue buena.

Omitiré la mención de decisiones, puesto que una decisión es una intención a la que se llega al final de un proceso de deliberación.

Parece que el enunciado

(G.2) Fue bueno por parte de Ulises el que viniera

es el mismo enunciado que (G.1). Por consiguiente, parece ser también el mismo enunciado que la conjunción (G.l.d). El primer conyunto, el fáctico "Ulises vino", es en cualquier caso parte del sentido ( $\mathrm{y}$, por tanto, de la estructura profunda) de (G.I) y de (G.2). Esto está claramente indicado por el tiempo pasado de indicativo, con su categoricidad palpable.

El enunciado (G.I) claramente elogia a Ulises. Puede inclusive pensarse que parte del enunciado es que Ulises tiene mucho que ver con la bondad de su venir qua evento o suceso en el mundo. Es decir, puede pensarse que parte del enunciado (G.I) es que el venir de Ulises fue el resultado de la intención de Ulises de venir. ${ }^{7}$ Estoy convencido de que esta proposición es parte del enunciado que uno a menudo quiere afirmar al usar la oración (G.1). Pero me inclino a pensar que tal enunciado puede formularse más perspicuamente de esta manera:

(G.3) Fue bueno de parte de Ulises que viniera intencionalmente

o de esta otra manera:

(G.4) Fue bueno por parte de Ulises que viniera como resultado de su tener intención de venir. ${ }^{8}$

7 Debo esta sugerencia a Charles Daniels.

8 Debo los ejemplos (G.3) y (G.4), así como la idea de su equivalencia, a Jack Meiland. 
No proporcionaré aquí un análisis completo de la proposición (G.1). Es suficiente, para mis propósitos en este artículo, que un análisis como (G.I.d) proporcione el esquema fundamental. Según dicho análisis, (G.I) ha de analizarse como la conjunción de ciertas proposiciones, uno de cuyos conyuntos es "la intención de Ulises de venir fue buena".

Esie esquiema posee el mérito de reducir la bondad aparentemente relacional de (G.1) a la bondad de una intención, a una bondad que en cualquier caso debemos tener en cuenta.

La pregunta ahora es: ¿qué son las intenciones, i.e., cuáles son los contenidos del tener intenciones? En particular, debemos preguntarnos: ¿Son las intenciones proposiciones? Si las intenciones son proposiciones, entonces podemos sostener, en virtud de (G.l.c), que la bondad relacional que se da entre los agentes y sus acciones es reducible a la bondad de las proposiciones. Por otro lado, si las intenciones no son proposiciones, entonces tenemos que investigar independientemente si la bondad de las intenciones es la misma propiedad que la bondad de las proposiciones. (Es un error concluir automáticamente que la bondad de las intenciones es diferente de la bondad de las proposiciones sólo porque las proposiciones y las intenciones son entidades diferentes.)

\section{Intenciones, proposiciones y practiciones}

El enunciado (G.I.d) es una conjunción, y cada conyunto es una proposición o enunciado (recuérdese que estamos utilizando estas dos palabras para referirnos a las mismas entidades). Tanto "Ulises vino" como "La intención de Ulises de venir fue buena" son proposiciones, pues (i) cada una de ellas es o verdadera o falsa, y (ii) cada una de ellas puede ser creída por alguna persona. Nuestro interés se enfoca sobre el último conjunto de (G.I.d):

(F.I) La intención de Ulises de venir fue buena.

Nuestro problema es fijar la entidad que, según $(F .1)$, posee bondad. En vistas a elaborar una respuesta, notemos que la palabra 'intención' funciona como una señal, desde fuera de la proposición $(F .1)$, por decirlo así, del tipo de entidad que según $(F .1)$ posee bondad. De manera similar, la expresión posesiva 'de Ulises' indica simplemente que la entidad que es la intención tiene a Ulises como componente: esta expresión es una señal de la copulación de sujeto y predicado, como cuando decimos "el color de Juan" o "la humanidad de Juan". Así pues, afirmo que la cláusula infinitiva: 
(Ulises)... venir

en la forma en que es usada en la oración 'La intención de Ulises de venir fue buena' presenta la entidad que es la intención y que según la proposición (F.I) es poseedora de bondad. En efecto, la cláusula que aparece en 'Fue bueno de parte de Ulises venir' y que a la vez formula la misma intención que es componente del enunciado (G.1), es la misma. La característica desconcertante de (G.I) reside en que la misma cláusula infinitiva, en el contexto de la oración (G.1), formula también la proposición "Ulises vino". Es esta doble función la que da cierta plausibilidad inicial a la afirmación de que (G.I) es el mismo enunciado que (G.2), en los que la bondad parece ser una relación entre Ulises y la proposición "Ulises vino". Pero si (G.2) es el mismo enunciado que (G.1), entonces debemos distinguir dos funciones diferentes en la cláusula '(Ulises) viniera' que aparece en el contexto de la oración 'Fue bueno de parte de Ulises que viniera': (i) la de formular la proposición "Ulises vino", que es implicada tanto por (G.1) como por (G.2), y (ii) la función de formular la intención que posee bondad. En ambos casos tenemos aún que determinar si la intención (en el sentido que nos ocupa) es o no una proposición.

Para evitar confusiones, fijemos la terminología. La palabra "intención' se usa aquí para referirse al "contenido" o, si se quiere, al "objeto" o al acusativo de un estado de tener intenciones. Así pues, mientras que tener intenciones es la contrapartida práctica de creer, una intención es la correspondiente contrapartida de una proposición. No es un simple accidente que la palabra 'intención' se use con el mismo tipo de ambigüedad que afecta al uso de la palabra 'creencia'. Pero el uso más típico de ambas palabras es para referirse a contenidos de pensamiento, no a estados mentales. De manera semejante, así como una misma proposición puede ser creencia, conjetura, suposición, premisa, o conclusión, así también un mismo contenido práctico puede ser intención o decisión.

Examinemos más de cerca la intención presentada por la oración

(F.I) La intención de Ulises de venir fue buena.

Esta intención, que es el contenido del estado o actitud de tener intenciones, por parte de Ulises, es una decisión que él expresaría, o que de hecho expresó, diciendo, quizás sólo a sí mismo: "Vendre" o "Voy a venir". Las intenciones son contenidos de pensamiento en primera persona, de manera que para presentar a la consideración de una tercera parte las intenciones de otro hombre, necesitamos un aparato lingüistico que tanto (i) presente una referencia en primera persona, como 
(ii) relacione esa referencia con su dueño o autor. En la oración ' $\mathrm{La}$ intención de Ulises de venir fue buena' la palabra 'intención' desempeña la función (i) y la expresión posesiva 'de Ulises' desempeña la función (ii). Así pues, dada la convención respecto a las comillas adoptada al principio de este artículo, la estructura de la frase nominal la intención de Ulises de venir' parece tener esencialmente la misma función que nuestras comillas dobles. Es decir, la frase nominal la intención de Ulises de venir' parece significar lo mismo que 'la intención "vendré" de Ulises'.

Ahora bien, si hay comillas dobles implícitas en 'la intención de Ulises de venir", entonces el enunciado (G.1.d), "Ulises vino y su intención de venir fue buena”, no es realmente el análisis de nuestro paradigma

(G.1) Fue bueno de parte de Ulises venir.

Este último enunciado no tiene ningunas comillas en su estructura interna o profunda, ni predica de ninguna intención el que sea una intención. Para ponerlo de otra manera, de acuerdo con el análisis anterior, con dobles comillas, de 'la intención de Ulises de venir', el enunciado (G.l.d) es un enunciado de segundo orden acerca de una intención, mientras que (G.l) es un enunciado de primer orden construido a partir de una intención. Pero la presente discusión ha traído a luz la estructura de (G.I): se trata de la aplicación de un operador o modalidad "es bueno que" a una intención de Ulises, no a un enunciado de que Ulises tiene determinada intención, ni a la concepción de esta intención.

No hay, sin embargo, en español ordinario, una forma obvia y expedita de exhibir el análisis estructural de (G.l) que remueva a Ulises del operador y que también, desde luego, deje a Ulises fuera de la intención en cuestión. Esta intención tiene como constituyente no a Ulises mismo sino la referencia de Ulises en primera persona. Podemos, ciertamente, inventar una notación especial. Podemos usar el nombre 'Ulises' como una mera señal que represente in viva persona las intenciones de Ulises, poniéndolo como subíndice de oraciones en primera persona, tiempo futuro. De esta manera, en nuestro ejemplo tenemos la oración '[(vendré en $T^{\prime}$ ) olses, $T$ ]' que puede representar la intención de Ulises de venir en el tiempo $T^{\prime}$, la cual él adoptó en el tiempo $T$. Con este aparato nuestro paradigma

(G.I) Fue bueno de parte de Ulises venir

puede ser representado más perspicuamente como: 
(G.1*) Para algunos tiempos $T$ y $T^{\prime}$ : Es bueno [(vendré en $T^{\prime}$ ) olises, $\eta$ ] y $T$ fue anterior a $T^{\prime}$ o ambos fueron simultáneos, y $T^{\prime}$ fue antes de ahora, y Ulises vino en $T^{\prime}$.

$\left(G .1^{*}\right)$ es patentemente más perspicuo en cinco respectos:

(i) separa el componente proposicional "Ulises vino" del componente intencional;

(ii) desembrolla las relaciones temporales que giran alrededor del tiempo pasado 'fue' (del verbo ser) y del infinitivo 'venir';

(iii) muestra que no nos encontramos frente a una bondad relacional sino únicamente frente a una bondad monádica;

(iv) exhibe la función de Ulises, en la totalidad de la estructura, como una mera coordenada que determina una intención; y

(v) revela el carácter de primer orden de nuestro paradigma.

Todas estas características se encuentran, por tanto, de una manera bella y compacta en la construcción del lenguaje ordinario 'Fue bueno de parte de Ulises venir'.

Ahora bien, las intenciones no son proposiciones, puesto que: (1) las intenciones carecen de valores de verdad, y (2) las intenciones no son acusativos o unidades de contenido del creer. Tener intenciones es análogo a creer, pero difiere en que toma como acusativos intenciones, no proposiciones. El creer, en su sentido más usual, es una disposición o propensión que (pace los conductistas) se ejercita en actos de pensar que determinado estado de cosas es el caso. De forma semejante, tener intenciones es, en su sentido más usual, una disposición o propensión que se ejercita en actos de decidir, y en afirmaciones o ensayos o prácticas de decisiones. Pero, a diferencia de creer, tener intenciones no es una propensión puramente intelectual, sino una propensión que ejercita la razón práctica: reordena las rutas motivacionales o causales que en el momento en cuestión constituyen a la persona de cuyo tener intenciones se trata. De momento, sin embargo, no estamos interesados en la psicología racional de la acción. ${ }^{9}$ Lo que nos ocupa aquí es la lógica y ontología de los objetos del tener intenciones. Nótese, sin embargo, que la palabra 'pensar' se usa a menudo neutralmente con respecto a lo puramente cognitivo y lo práctico-cognitivo. Así pues, es correcto decir que las creencias, o los actos de creer, son ejercitadas en actos de pensar, y también que los estados de tener intención (o las intenciones, en el sentido de actitud, no de objeto o acusativo) son ejercitados en actos de

9 Véase Thinking and Doing, caps. 10 y 12. 
pensar. Pero mientras los primeros son actos de pensar estados de cosas (esto es, actos cuyos acusativos se formulan mediante cláusulas subordinadas con el verbo en el modo indicativo), los segundos, sin embargo, son actos de pensar qué hacer (esto es, actos cuyos acusativos se formulan en cláusulas subordinadas con el verbo en infinitivo), e.g., "Julieta pensaba venir a México".

Hay una tercera diferencia entre proposiciones e intenciones: (3) las intenciones no son condiciones, ni necesarias ni suficientes; no pueden ser formuladas por cláusulas que estén subordinadas a partículas condicionantes como 'si', 'a condición de que', 'sólo si', etc. Una intención es a menudo formulada por medio de una oración en tiempo futuro. Por ejemplo, un hombre puede tomar una decisión diciendo: "Vendré mañana". Su decisión -una intención - difiere de su predicción de que vendrá - una proposición - en que: (1) carece de valor de verdad, y (2) no es un objeto de su creencia. Por otro lado, si ese hombre dice: "si viniera mañana, entonces...", la cláusula en tiempo futuro que sigue a la pronunciación de la palabra 'si' no formulará una decisión. La cláusula formulará una proposición que el hablante sostendrá ser una condición de hecho y suficiente para cualquier cosa que sea formulada en el consecuente de su afirmación condicional, y, desde luego, este consecuente puede muy bien ser una intención.

La característica (3) es importante porque algunos filósofos han hablado de enunciados o proposiciones que no tienen valor de verdad. Pero aunque la carencia de valores de verdad no fuese suficiente para establecer que las intenciones no son especies de proposiciones, las características (2) y (3) ciertamente lo establecen con toda fuerza.

Carecer de valores de verdad es, sin embargo, crucial para las intenciones. Si una proposición $P$ no tiene valor de verdad, entonces (a) su negación no- $P$ tiene valor de verdad, o bien, (b) no- $P$ no tiene valor de verdad. En el caso (a) podemos aún distinguir las proposiciones de las intenciones por medio de los valores de verdad porque la negación de una intención, que es ella misma una intención, carece también de valor de verdad. En el caso (b), o bien (b.1) la proposición que es la disyunción de $P$ y no- $P$ es una tautología y tiene el valor verdad, o (b.2) esa disyunción no tiene valor de verdad. En el caso (b.1), las intenciones y las proposiciones son entidades diferentes, puesto que la disyunción de una intención y su negación es tautológica, pero no es verdadera. Los contenidos de pensamiento sin valor de verdad, como las intenciones y las órdenes, son tautológicos cuando tienen la forma de una tautología expresable en una tabla de verdad..$^{10}$ En el caso (b.2)

10 Para más argumentos a favor de la distinción entre proposiciones e intenciones, 
hay una disyunción de $P$ y no- $P$ y alguna otra proposición, quizás no-no- $P$, tal que esa disyunción de tres miembros es verdadera, lógicamente verdadera. Por otro lado, si las intenciones tuviesen tres valores, sus disyunciones tautológicas tampoco serían verdaderas. Las intenciones carecen absolutamente de valores de verdad: ningún complejo de intenciones construido sólo mediante conectivos tiene valor de verdad.

Las intenciones son contenidos de pensamiento práctico en primera persona. Cuando el pensamiento en cuestión es un acto de pensar, es un acto de decidir o de reafirmar o ensayar una decisión tomada con anterioridad. Cuando el pensamiento en cuestión es disposicional, i.e., una propensión a reafirmar decisiones y a ejecutar los actos presentados en esas decisiones, la propensión es una actitud de tener intenciones de, o de poseer una intención. Peró los contenidos de pensamiento son los mismos: (a) contenidos sin valor de verdad, (b) en primera persona, (c) expresables con oraciones de la forma ' $A$-ré' o 'haré $A$ ' (en que ' $r e ́$ ' es la terminación del tiempo futuro, primera persona singular, de un verbo dado, y ' $A$ ' representa, en su primera aparición, el radical de un verbo, y en su segunda aparición una acción dada), dependiendo del dialecto del hablante. ${ }^{11}$

Las intenciones o decisiones (en cuanto contenidos o acusativos de primera persona del pensar práctico) complementan los consejos, peticiones, órdenes, y los contenidos de segunda persona de los actos de consejo razonado, en que se le dice a una persona, con razones, qué hacer. Anteriormente ${ }^{12}$ he usado el término 'mandato' como término genérico para agrupar todos los contenidos de segunda persona de dichos actos, y el término 'prescripción' para referirme a la estructura común a una familia de mandatos que demandan de los mismos agentes el hacer las mismas acciones en exactamente las mismas circunstancias. Por ejemplo, la orden "Pedro, vete a la casa", y el consejo "Pedro, vete a la casa" (pronunciado con el tono de voz apropiado), y el ruego "Pedro, por favor vete a la casa", asumiendo, desde luego, que en todos tenemos el mismo Pedro y el mismo tiempo, tienen como estructura subyacente la prescripción "Pedro vete a la casa" - claramente expresada por la ausencia de la usual coma, denotadora del imperativo, después de 'Pedro', o por la cláusula infinitiva "Pedro ir(se) a la casa". Esta forma infinitiva aparece en la oración deóntica 'Pedro debe ir(se) a la casa' que muestra cómo el operador deóntico 'debe' se aplica a la prescripción Pedro ir(se)

véase mi "Intentions and Intending", American Philosophical Quarterly, 9 (1972), 139-149, y especialmente Thinking and Doing, caps. 6 y 10.

11 Para un argumento detallado y formal en defensa de la estructura bivalente de la lógica de imperativos, véase Thinking and Doing, cap. 4.

12 Véase Thinking and Doing, caps. 2 y 4 . 
a la casa..$^{13}$ Llamaré a la clase de las prescripciones y las intenciones practiciones. Las intenciones son practiciones en primera persona. Son contrapartidas, en primera persona de los mandatos. Pero no son mandatos en primera persona. ${ }^{14} \mathrm{El}$ contraste fundamental que aquí nos ocupa no es entre intenciones y proposiciones, sino entre practiciones y proposiciones.

\section{Dos tipos de bondad}

Tenemos, entonces, dos tipos de entidad que son concebidos como buenos: proposiciones e intenciones. Nuestra pregunta apremiante ahora resulta ser:

¿Es la bondad de una proposición la misma propiedad ( $u$ operador o modalidad) que la bondad de una intención? ¿o tenemos dos diferentes propiedades (u operadores)?

De! simple hecho de que las intenciones no sean proposiciones no se sigue que la propiedad adscrita a las intenciones por medio del adjetivo 'bueno' o, más bien, del prefijo 'es bueno que', sea diferente de la propiedad adscrita a las proposiciones por medio del mismo adjetivo u operador. No tengo en realidad ningún argumento contundente para probar que la respuesta deba ser afirmativa, o que deba ser negativa. Pero tengo un argumento que, creo, presta un sólido $e$ insólito apoyo a la afirmación de que la bondad de intenciones es una propiedad ( $u$ operador) diferente de la bondad de proposiciones. A continuación lo presento.

Considérese la siguiente proposición:

(G.11) Seria bueno de parte de Ulises hacer lo siguiente: pedir disculpas a Penélope por carta a menos que los carteros se declaren en huelga.

Parece perfectamente claro que $(G .11)$ es equivalente, aunque no idéntica, a la proposición:

13 Véase Thinking and Doing, cap. 7.

14 Para problemas relacionados con la referencia demostrativa o indéxica, y para una defensa de la tesis de que las proposiciones en primera persona son irreductibles a proposiciones en segunda y tercera persona, sean éstas demostrativas o no, véanse mis ensayos "Indicators and Quasi-Indicators", The Journal of Philosophy, 65, $\mathrm{n}^{\circ} 15$ (Aug. 1968), 439-406, y “'Be': A Study in the Logic of Self-Consciousness", Ratio 8 (1966), 130-157. 
(G.11.a) A menos que los carteros se declaren en huelga, sería bueno de parte de Ulises pedir disculpas a Penélope por carta.

Lo interesante de esta equivalencia es que, mientras en (G.11) la bondad se adscribe a la intención disyuntiva "Ulises... pedir disculpas a Penélope por carta a menos que los carteros se declaren en huelga" como un todo, en (G.11.a) la bondad se adscribe solamente al disyunto "Ulises... pedir disculpas a Penélope por carta". Por otro lado, (G.11) no es equivalente a:

(G.12) Sería bueno de parte de Ulises pedir disculpas a Penélope por carta o pedir disculpas por cable.

Ni (G.12) implica (G.11), ni (G.11) implica (G.12). Además, (G.12) no es equivalente $y$, a fortiori, no es idéntica a:

(G.12.a') O Ulises pide (pedirá) disculpas a Penélope por carta, o sería bueno de parte de Ulises pedir disculpas a Penélope por cable.

De manera semejante, (G.12) no es equivalente a

(G.12.a") O Ulises pide (pedirá) disculpas a Penélope por cable, o sería bueno de parte de Ulises pedir disculpas a Penélope por carta.

Por otro lado, (G.12) es equivalente, aunque no idéntica, a

(G.12.a) O sería bueno de parte de Ulises pedir disculpas a Penélope por carta, o sería bueno de parte de Ulises pedir disculpas a Penélope por cable.

Los ejemplos anteriores ilustran $y$, por consiguiente, proporcionan evidencia sólida a favor de los siguientes principios, en que ' $k$ ' representa un conectivo cualquiera, ' $p$ ' representa proposiciones e ' $i$ ' intenciones, siendo los ejemplos de ' $p$ ' oraciones en el modo indicativo y los de ' $i$ ' cláusulas infinitivas cuyos sujetos son los ejemplos de ' $X$ ':

1.1 Los prefijos sintácticos de la forma 'fue (es, sería, será) bueno de parte de $X^{\prime}$ expresan modalidades que toman intenciones como argumentos y tienen proposiciones como valores. 
Así, por ejemplo, "Fue bueno de parte de María visitar a Pedro" es una proposición, pero, como se hizo notar arriba, el segmento 'María visitar a Pedro' formula la intención "(Visitaré a Pedro) marfa".

1.2 Una estructura conectiva que tiene como componentes inmediatos una proposición y una intención es una intención, esto es, pki e $i k p$ son intenciones.

G1.2. "Es bueno de parte de $X$ que $(p \circ i)$ " es equivalente a " $p$ o es bueno de parte de $X$ que $i$ ".

Ahora bien, a semejanza de G1.2 tenemos:

GP.2. "Es bueno que $(p \circ q)$ " es equivalente a "es bueno que $p$ o es bueno que $q$ ".

Obviamente, un principio que gobierna tanto proposiciones como intenciones es éste, en que '* $p$ ' y ' $q$ ' representan proposiciones o intenciones, según el caso:

GP1.3. Si * $p$ es equivalente a * $q$, entonces "es bueno que * $p$ " es equivalente a "es bueno que * $q$ ".

Con 'equivalencia' me refiero, desde luego, a la coimplicación lógica en el sentido requerido por la lógica de intenciones y la lógica de las propiedades $u$ operadores (o modalidades) de valor. Obviamente, equivalencia no es identidad.

Los principios anteriores sirven de ayuda en la construcción de un argumento preliminar en apoyo de la tesis $E$ de que la bondad de las intenciones es una propiedad ( $u$ operador) diferente de la bondad de las proposiciones. Asumimos aquí que la lógica de intenciones es bivalente y paralela a la lógica de proposiciones. En otro ensayo ${ }^{15}$ he argumentado en detalle a favor de esta posición. Para defender la tesis $E$ mediante una reductio ad absurdum, supóngase que la bondad de las proposiciones es idéntica a la bondad de las intenciones, y considérese la siguiente deducción, en que la equivalencia se representa con doble flecha, y tanto las comillas normales como las comillas de Quine se dejan implícitas. 'Es bueno que' se abrevia con 'bueno', por conveniencia:

1. $p \leftrightarrow p \vee(p \& i)$

2. Bueno $(p) \leftrightarrow$ bueno $p \vee(p \& i)$

tautologia

3. Bueno $(p) \leftrightarrow p \vee$ bueno $(p \& i)$ por GP1.3 por $G 1.2$ y 1.2

15 Véase la nota 10. 
Es claro que la propuesta equivalencia 3 es falsa. Muy bien puede ser el caso que $p$ sea verdadera, aunque ni $p$ ni $p \& i$ sean buenas. Más especificamente, de 3 se sigue que "es bueno que $p$, si $p$ ", es decir, todo estado de hechos realizado es bueno. Obviamente, 3 implica:

4. $p \mathrm{v}$ bueno $(p \& i) \rightarrow$ bueno $(p)$

Por tanto:

5. $p \rightarrow$ bueno $(p)$

Esto es claramente falso.

Una réplica al argumento anterior es que el principio GPI.3 necesita una restricción:

GPl.2 Si * $p$ y ${ }^{*} q$ son equivalentes $y, o$ ambas son proposiciones o ambas son intenciones, entonces "bueno (" $p)$ " es equivalente a "bueno (*q)".

De esta manera podemos bloquear el paso de 1 a 2 en la deducción anterior, ya que por el principio $1.2, p \vee(p \& i)$ es una intención.

Ahora bien, es natural suponer que la bondad que se aplica a proposiciones se aplica también a las proposiciones que atribuyen bondad a otras proposiciones. Esto sugiere cadenas infinitas de proposiciones de valor. Si "Bueno $(p)$ " es verdadera, también lo son "Bueno (bueno $(p)) ", \ldots$ Para evitar tener que manejar infinidad de valores, parece natural suponer que sólo se necesita medir el primer miembro de cada cadena para determinar el valor total que el universo gana cuando cierta proposición es verdadera. En otro estudio, ${ }^{16}$ he tratado algunos de los problemas relacionados con la medición de valores. Aquí solamente necesitamos mencionar el principio siguiente:

GP.4. "Bueno (bueno ("p)) es equivalente a "Bueno (" $p)$ ".

Considérese, pues, la siguiente deducción, en que 'es bueno que' se abreviará como ' $B$ ' y en que se supone, para efectuar una reductio ad absurdum, que la bondad de las proposiciones es la misma que la bondad de las intenciones.
11. $B(p \vee i) \leftrightarrow p \vee B(i)$
G1.2
12. $B(B(p \vee i) \leftrightarrow B(p \vee B(i))$
$11, G P 1.2$

16 Véase el artículo mencionado en la nota 4. 

13. $B(p \vee i) \leftrightarrow B(p) \vee B(B(i))$
$12, G P .2, G P .4$
14. $B(p \vee i) \leftrightarrow B(p) \vee B(i)$
$13, G P .4$
15. $p \vee B(i) \leftrightarrow B(p) \vee B(i)$
11, 14; Lógica proposicional

Evidentemente, 15 es falso, pues un estado de cosas bueno (esto es, $B(p)$ es verdadero) puede no estar realizado, es decir, $p$ es falso, mientras que algunas intenciones no son buenas, esto es, $B(i)$ es falso.

La réplica inmediata a esa deducción es rechazar la tesis de que hay proposiciones que atribuyen bondad a proposiciones que a su vez atribuyen bondad a otra proposición o a una intención. De esta manera el paso 12 queda bloqueado. ¿Podemos, por tanto, sostener que la bondad de proposiciones es la misma que la bondad de intenciones? No lo creo. Me parece que las conjunciones mixtas de intenciones y proposiciones se regulan por el siguiente principio:

G1.5. "Es bueno de parte de $X(A$-ar \& $p)$ " es equivalente a " $p$ \& es bueno de parte de $X A$-ar" (en que ' $A$ ' representa el radical y ' $A$-ar' el infinitivo de un verbo cualquiera).

En $G 1.5$, el símbolo '\&' de conjunción y la expresión ' $A$-ar \& $p)$ ' pueden leerse de diferentes maneras, dependiendo del ejemplo en cuestión. Hay, sin embargo, dos lecturas generales que encuentro interesantes: (i) ' $A$-ar mientras es el caso que $p$ ' y (ii) ' $A$-ar, siendo el caso que $p$ '. Es digno de notarse que si bien 'mientras' es a menudo un genuino adverbio subordinante de tiempo (en terminología de los gramáticos), 'mientras es el caso que' es una expresión de conjunción lógica mixta, y no tiene nada que ver con el tiempo. Considérese, por ejemplo, "Napoleón estaba enfermo mientras es el caso que el Dr. Pérez ganará (ganó) las elecciones".

Sea o no iterativa la bondad de las proposiciones, debemos reconocer este principio:

GP.6. "Es bueno que o bien sea bueno que $q$ o bien $p$ " es equivalente a "o bien es bueno que $q$ o bien es bueno que $p$ ".

Asúmase una vez más que la bondad de las proposiciones es la misma que la bondad de las intenciones; recuérdense las abreviaturas anteriores y considérese el siguiente argumento:
31. $p \leftrightarrow(p \& B(i)) \vee p$
tautología
32. $p \leftrightarrow B(p \& i) \vee p$
G1.5
33. $B(p) \leftrightarrow B(B(p \& i) \mathbf{v} p)$
GPl.2 


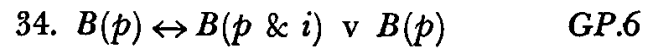

35. $B(p) \leftrightarrow(p \& B(i)) \vee B(p) \quad G 1.5$

Palpablemente, 35 es falso en caso de que $p \& B(i)$ sea verdadero y de que $B(p)$ sea falso, como muy bien puede suceder.

Me parece que la totalidad de los argumentos dados muestra que la bondad de las intenciones es una propiedad o modalidad diferente de la bondad de las proposiciones. La bondad adscrita a la disyunción mixta de intenciones y proposiciones en (G.11) no tiene nada que ver con el componente proposicional de esa disyunción. Tal componente proposicional no puede ser foco o sujeto de la bondad adscrita a toda la disyunción que es necesariamente adscribible a cada componente intencional. Así pues, si las proposiciones no pueden ser focos o sujetos de la bondad de las intenciones, entonces la bondad de que pueden ser focos es diferente de la que es adscribible a las intenciones.

\section{Dos objeciones}

Una premisa de mi argumento en la sección anterior ha sido atacada. Se ha sugerido que (G.11), "Serla bueno de parte de Ulises hacer lo siguiente: pedir disculpas a Penélope por carta a menos que los carteros se declaren en huelga" y (G.11.a), "A menos que los carteros se declaren en huelga, sería bueno de parte de Ulises pedir disculpas a Penélope por carta", difieren sólo en el orden de sus disyuntos, que en (G.11) el disyunto proposicional "los carteros se declaren en huelga" no está dentro del alcance de 'bondad', i.e., el operador "sería bueno de parte de Ulises que". En otras palabras, según esta crítica mi puntuación de la oración (G.11) es incorrecta; debería ser 'Sería bueno de parte de Ulises hacer lo siguiente: pedir disculpas a Penélope por carta; a menos que los carteros se declaren en huelga'. ${ }^{17}$

Tal sugerencia no funciona. Hay proposiciones en que la bondad se adscribe a una intención compuesta mixta, de manera que hay la proposición (G.11) como la describí arriba. Para reafirmar esto, considérese

(G.13) Sería bueno de parte de Juan hacer lo siguiente: tanto pasar por María a la estación si ella viene como hablar con Mirna si ella llama.

17 Esta sugerencia me fue hecha en clase por James Tomserlin y David MacCaskill en 1967. 
En este caso la intención compleja a la que se adscribe bondad es una conjunción, y cada conyunto es una intención condicional con una proposición, en cursivas, como antecedente. Obviamente, no se puede mostrar que la proposición "María viene" no está bajo el alcance de la bondad simplemente cambiando la puntuación de la oración (G.13). Alguien podría sugerir que la oración $(G .13)$ es simplemente una abreviatura de la oración

(G.14) Sería bueno de parte de Juan pasar por María, si ella viene; y también sería bueno de parte de Juan hablar con Mirna, si ella llama.

(G.13) es una abreviación de (G.14), alguien puede decir, en la misma forma en que (a) 'Juan y María están aqui' es una abreviación de (b) 'Juan está aquí y María está aqui'. Pero esta sugerencia no viene al caso. El enunciado (G.14) puede ser verdadero mientras (G.13) es falso. En general, para decirlo globalmente, del hecho de que dos intenciones sean por separado, individualmente, buenas, no se sigue que la conjunción de ellas sea también buena. Y esto es verdadero, sean las intenciones en cuestión condicionales o no.

Varios amigos ${ }^{18}$ me han sugerido que debería considerar la alternativa de que (G.13) sea simplemente una variante estilística de

(G.15) Si María viene y Mirna llama, sería bueno de parte de Juan tanto pasar por María a la estación como hablar con Mirna.

Si esta alternativa fuese correcta, entonces mi réplica a la objeción se derrumba, pues las proposiciones "María viene" y "Mirna llama" no están realmente dentro del alcance del operador o propiedad de bondad. Encuentro, sin embargo, que (G.13) y (G.15) no son equivalentes, por la siguiente razón: si María viene y Mirna llama no podemos inferir de (G.13) que sería bueno de parte de Juan tanto pasar por María como hablar con Mirna. En dicho caso, en cambio esta conclusión puede derivarse de (G.15) por medio de un sencillo modus ponens. Estoy dando por sentado que:

GPI.7. "Es bueno que $(p \& \sim p)$ " y sería bueno de parte de $X(A$-ar \& $\sim A$-ar) son falsas, y lo son necesariamente.

Una segunda objeción a mi argumento de la sección III intenta destruirlo atacando su conclusión. Es la siguiente: ${ }^{19}$ podemos sin agramaticalidad decir en español:

18 Especialmente Romane Clark y Paul Eisenberg.

10 Debo esta objeción a Rollin Workman. 
(G.16) Fue bueno de parte de Julieta venir y que nosotros estuviéramos todavía ahí cuando ella llegó.

Evidentemente, en la medida en que uno siente que (G.16) es gramaticalmente correcta, uno siente que el prefijo 'fue bueno' expresa exactamente el mismo concepto, sea éste propiedad u operador. Sin embargo, aunque creo y me encantaría sostener que (G.16) es agramatical, no es mi intención sostener eso aquí. Me contento con rechazar la premisa que liga la gramaticalidad de (G.16) con la tesis semántica de que no hay ambigüedad en el prefijo 'fue bueno'. Quiero mantener que 'fue bueno' es ambiguo entre 'fue bueno de parte de Julieta' y 'fue bueno que'. Es sintomático que la ambigüedad sea una parte necesaria de la interpretación adecuada de la oración. En pocas palabras, sostengo que (G.16) es una abreviación, en la gramática superficial, de

(G.16.a) Fue bueno de parte de Julieta venir y fue bueno que nosotros estuviéramos todavía ahí cuando ella llegó.

Sostengo que las locuciones 'fue bueno de parte de' y 'fue bueno que' expresan diferentes bondades, la primera de intenciones, la segunda de proposiciones.

\section{Conclusión}

He argüido que: (I) las intenciones y las proposiciones son entidades mutuamente irreducibles; y (II) la bondad de las intenciones es una propiedad u operador totalmente diferente de la bondad de las proposiciones.

Hablaré de bondad proposicional o fáctica para referirme a la bondad adscribible a las proposiciones, y de bondad deóntica o accional para referirme a la bondad adscribible a intenciones. Podemos hablar de propiedades de valor para referirnos a la bondad proposicional y a las propiedades definibles o explicables en términos de la bondad proposicional o fáctica. Podemos hablar de propiedades deónticas para referirnos a la bondad accional y a las propiedades definibles en términos de la bondad deóntica. Hablaré de propiedades de valor puras (y de propiedades deónticas puras) para referirme a propiedades definidas únicamente en términos de bondad proposicional (o de bondad deóntica) y de relaciones lógicas.

Llamo deóntica a la bondad intencional porque el argumento anterior muestra que la bondad involucrada en nuestro paradigma (G.1), "Fue bueno de parte de Ulises venir", es del mismo tipo que la correc- 
ción, el deber, y la incorrección, las cuales, como he sostenido desde hace ya mucho tiempo, son operadores de practiciones. ${ }^{20} \mathrm{He}$ sostenido que las propiedades deónticas, así llamadas a veces, son operadores de prescripciones cuyos valores son proposiciones. Fue una agradable sorpresa encontrar que hay una bondad que es un operador de practiciones en primera persona y que da proposiciones, y que hay oira bondad que opera sobre proposiciones y da también proposiciones. Así pues, una pregunta que se presenta es: ¿Cuáles son las relaciones de la bondad accional respecto de los otros miembros de la familia deóntica?

Esta pregunta tiene que dejarse para otra ocasión.

20 Véanse los estudios citados en las notas 5 y 10 . Este principio crucial que liga prescripciones (o mandatos) con proposiciones ha caracterizado mi concepción de la lógica deóntica como no estándar desde 1952, cuando preparé On the Logic of Commands, ensayo de maestría presentado en la Universidad de Minnesota. Evidencia adicional aparece en Thinking and Doing, caps. 6 y 7. 